\title{
Wind Velocity Vertical Extrapolation by Extended Power Law
}

\author{
Zekai Şen, Abdüsselam Altunkaynak, and Tarkan Erdik \\ Hydraulics Division, Civil Engineering Faculty, Istanbul Technical University, Maslak, 34469 Istanbul, Turkey \\ Correspondence should be addressed to Tarkan Erdik, tarkanerdik@hotmail.com
}

Received 19 August 2012; Accepted 7 October 2012

Academic Editor: Harry D. Kambezidis

Copyright () 2012 Zekai Şen et al. This is an open access article distributed under the Creative Commons Attribution License, which permits unrestricted use, distribution, and reproduction in any medium, provided the original work is properly cited.

\begin{abstract}
Wind energy gains more attention day by day as one of the clean renewable energy resources. We predicted wind speed vertical extrapolation by using extended power law. In this study, an extended vertical wind velocity extrapolation formulation is derived on the basis of perturbation theory by considering power law and Weibull wind speed probability distribution function. In the proposed methodology not only the mean values of the wind speeds at different elevations but also their standard deviations and the cross-correlation coefficient between different elevations are taken into consideration. The application of the presented methodology is performed for wind speed measurements at Karaburun/Istanbul, Turkey. At this location, hourly wind speed measurements are available for three different heights above the earth surface.
\end{abstract}

\section{Introduction}

Wind energy, as one of the main renewable energy sources in the world, attracts attention in many countries as the efficient turbine technology develops. Wind speed extrapolation might be regarded as one of the most critical uncertainty factor affecting the wind power assessment, when considering the increasing size of modern multi-MW wind turbines. If the wind speed measurements at heights relevant to wind energy exploitation lacks, it is often necessary to extrapolate observed wind speeds from the available heights to turbine hub height [1], which causes some critical errors between estimated and actual energy output, if the wind shear coefficient, $n$, cannot be determined correctly. The difference between the predicted and observed wind energy production might be up to $40 \%$, due to turbulence effects, time interval of wind data measurement, and the extrapolation of the data from reference height to hub heights [2].

In the literature, the wind shear coefficient is generally approximated between 0.14 and 0.2. However, in real situations, a wind shear coefficient is not constant and depends on numerous factors, including atmospheric conditions, temperature, pressure, humidity, time of day, seasons of the year, the mean wind speed, direction, and nature of terrain [3-6]. Table 1 demonstrates the various wind shear coefficients for different types of topography and geography [3].

According to the calculations of wind resource analysis program (WRAP) report, in 39 different regions, out of 7082 different wind shear coefficients, $7.3 \%$ are distributed between 0 and 0.14 and $91.9 \%$ above 0.14 , while $0.8 \%$ are calculated as negative [7], due to the measurements error.

Different methods have been developed to analyze wind speed profiles, such as power, logarithmic, and loglinear laws [8]. Besides, in the literature various studies are conducted in order to estimate wind shear coefficient in the power law only if surface data is available at hand [9-11].

The wind speed undergoes repeated changes, as a result of which the roughness and friction coefficients also change depending on landscape features, the time of the day, the temperature, height and wind direction. The uncertainty is inhereted in the wind speed data and its extrapolation to the hub height should be considered carefully and preciously [12]. Moreover, this uncertainty is exacerbated in the offshore environment by the inclusion of the dynamic surface [13]. Therefore, the mean wind speed profile of the logarithmic type is developed by applying a stability correction for offshore sites [14].

It is crucial point for energy investors to accurately predict the average wind speed at different wind turbine 
TABLE 1: Wind shear coefficient of various terrains [3].

\begin{tabular}{lc}
\hline Terrain type & \\
\hline Lake, ocean, and smooth-hard ground & 0.1 \\
Foot-high grass on level ground & 0.15 \\
Tall crops, hedges, and shrubs & 0.2 \\
Wooded country with many trees & 0.25 \\
Small town with some trees and shrubs & 0.3 \\
City area with tall buildings & 0.4 \\
\hline
\end{tabular}

hub heights and make realistic feasibility projects for these heights. In this study, a simple but effective methodology on the basis of the perturbation theory is presented in order to derive an extended power law for the vertical wind speed extrapolation and then the Weibull probability distribution function (pdf) parameters. It is observed that on the contrary to the classical approach not only the means of wind speeds are at different elevations, but also the standard deviations and the cross-correlation coefficient should be taken into consideration, if the wind speeds at different elevations are not independent from each other.

\section{Power Law}

This law is the simplest way for estimating the wind speed at a wind generator hub elevation from measurements at a reference level. In general, the power law expression is given as,

$$
\left(\frac{Z_{1}}{Z_{2}}\right)^{n}=\left(\frac{V_{1}}{V_{2}}\right)
$$

where terms in the brackets are the velocity and elevation ratios, $V_{2}>V_{1}$ and $Z_{2} / Z_{1}$, respectively. Furthermore, $V_{2}>$ $V_{1}$ and $Z_{2}>Z_{1}$; and $n$ is the exponent of the power law, which is a complex function of the local climatology, topography, surface roughness, environmental conditions, meteorological lapse rate, and weather stability. It is clear that the effects of all these factors are embedded in the wind velocity time records, and consequently, their total reflections are also expected in the value of the exponent, $n$. Therefore, one tends to think whether there is a way of obtaining the estimation of this exponent from the wind speed time series. Power laws are used almost exclusively without any generally accepted methodology. Most often, only the arithmetic averages of the wind speed at two elevations are considered in the numerical calculation of the exponent. Logically, other than the mean values, standard deviations and cross-correlation coefficient should enter the calculations, because these additional parameters arise as a result of instability, roughness, and so forth. Provided that there are wind speed records at two or more elevations, the following approach provides an objective solution.

\section{Extended Power Law}

In (1), the only random variable that represents the weather situation is the wind speeds, which can be written in terms of the averages and perturbation terms about their averages that render (1) to

$$
\left(\frac{Z_{1}}{Z_{2}}\right)^{n}=\left(\frac{\overline{V_{1}}+V_{1}^{\prime}}{\overline{V_{2}}+V_{2}^{\prime}}\right)
$$

where $V_{1}^{\prime}$ and $V_{2}^{\prime}$ are the perturbation terms with averages equal to zero, $\overline{V_{1}^{\prime}}=\overline{V_{2}^{\prime}}=0$. This last expression can be rewritten simply as

$$
\left(\frac{Z_{1}}{Z_{2}}\right)^{n}=\left(\overline{\overline{V_{1}}}\right)\left(1+\frac{V_{1}^{\prime}}{\overline{V_{2}}}\right)\left(1+\frac{V_{2}^{\prime}}{\overline{V_{2}}}\right)^{-1} .
$$

This expression is referred to as the extended power law in this paper. The third bracket on the right-hand side corresponds to a geometric series, which can be expressed by the Binomial expansion as

$$
\begin{aligned}
\left(\frac{Z_{1}}{Z_{2}}\right)^{n}=\left(\frac{\overline{V_{1}}}{\overline{V_{2}}}\right)\left(1+\frac{V_{1}^{\prime}}{\overline{V_{1}}}\right) & {\left[1-\left(\frac{V_{2}^{\prime}}{\bar{V}_{2}}\right)+\left(\frac{V_{2}^{\prime}}{\bar{V}_{2}}\right)^{2}\right.} \\
& \left.-\left(\frac{V_{2}^{\prime}}{\bar{V}_{2}}\right)^{3}+\left(\frac{V_{2}^{\prime}}{\bar{V}_{2}}\right)^{4}-\cdots\right] .
\end{aligned}
$$

This expression can still be simplified after the expansion of the second and third brackets on the right-hand side and then by considering the second-order term approximately yields

$$
\begin{aligned}
\left(\frac{Z_{1}}{Z_{2}}\right)^{n}=\left(\frac{\bar{V}_{1}}{\bar{V}_{2}}\right) & {\left[1-\left(\frac{V_{2}^{\prime}}{\bar{V}_{2}}\right)+\left(\frac{V_{2}^{\prime}}{\bar{V}_{2}}\right)^{2}+\left(\frac{V_{1}^{\prime}}{\bar{V}_{1}}\right)\right.} \\
& \left.-\left(\frac{V_{1}^{\prime}}{\bar{V}_{1}}\right)\left(\frac{V_{2}^{\prime}}{\bar{V}_{2}}\right)+\frac{V_{1}^{\prime}}{\bar{V}_{1}}\left(\frac{V_{2}^{\prime}}{\bar{V}_{2}}\right)^{2}\right] .
\end{aligned}
$$

After taking the arithmetic averages of both sides and then considering that the odd order power term averages are equal to zero, (5) yields to

$$
\left(\frac{Z_{1}}{Z_{2}}\right)^{n}=\left(\frac{\bar{V}_{1}}{\bar{V}_{2}}\right)\left[1-\frac{V_{1}^{\prime}}{\bar{V}_{1}} \frac{V_{2}^{\prime}}{\bar{V}_{2}}+\left(\frac{V_{2}^{\prime}}{\bar{V}_{2}}\right)^{2}\right] .
$$

By definition $\overline{V_{1}^{\prime}}=\overline{V_{2}^{\prime}}=0$, exactly. In fact, for symmetrical (i.e., Gaussian) perturbation terms, the odd number arithmetic averages such as $\overline{V_{1}^{\prime} V_{2}^{\prime 2}}$ are also equal to zero approximately by definition.

In (6), the common arithmetic average of the perturbation multiplication, $\overline{V_{1}^{\prime} V_{2}^{\prime}}$, at two different elevations is equal to the covariance of the perturbations. This can be written in terms of the standard deviations $S_{V_{1}}$ and $S_{V_{2}}$ and crosscorrelation, $r_{12}$, multiplication as $\overline{V_{1}^{\prime} V_{2}^{\prime}}=r_{12} S_{V_{1}} S_{V_{2}}$. The second-order perturbation term average, $\overline{V_{2}^{\prime 2}}$, is equivalent to the variance of the perturbation term as $\overline{V_{2}^{\prime 2}}=S_{V_{2}}^{2}$. The substitution of these last two expressions into (6) leads to

$$
\left(\frac{Z_{1}}{Z_{2}}\right)^{n}=\left(\frac{\overline{V_{1}}}{\overline{V_{2}}}\right)\left(1-\frac{S_{V_{1}} S_{V_{2}}}{\overline{V_{1} V_{2}}} r_{12}+\frac{S_{V_{1}}^{2}}{{\overline{V_{2}}}^{2}}\right),
$$




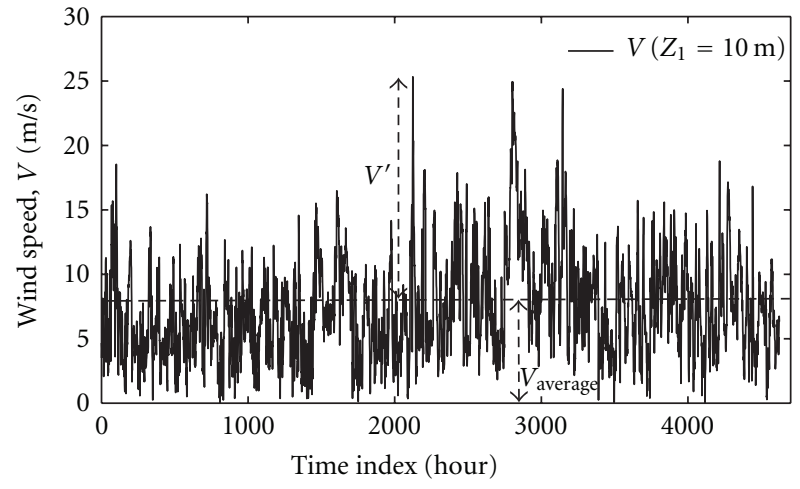

(a)

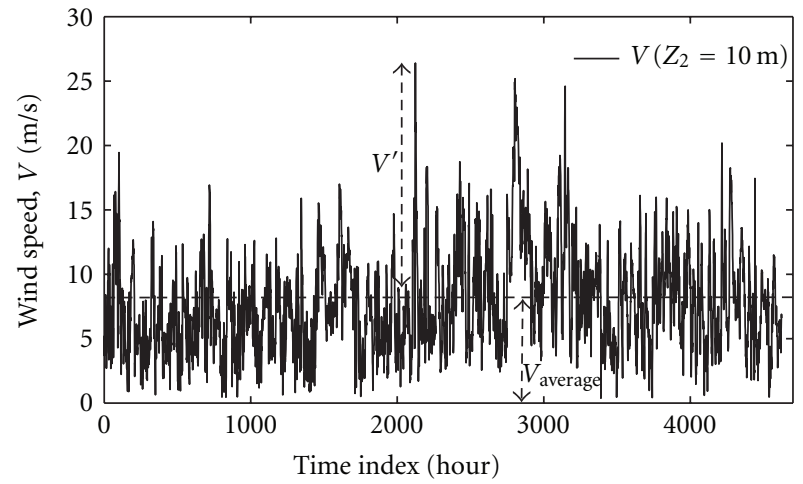

(b)

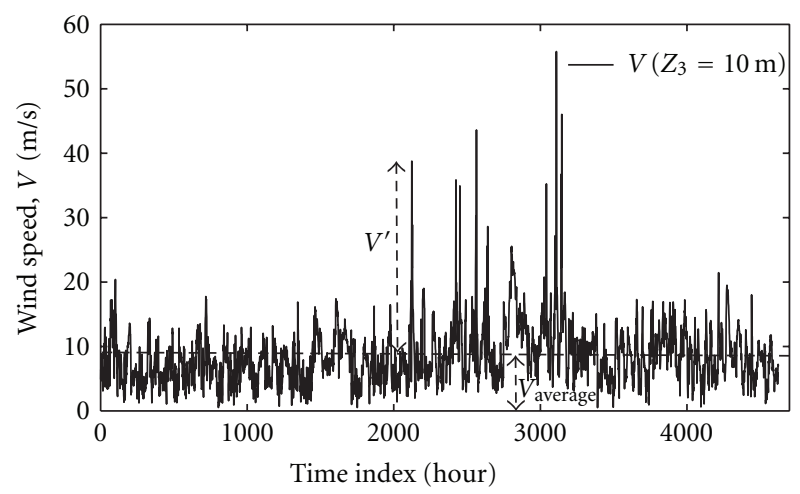

(c)

FIGURE 1: Karaburun wind speed records at different levels.

where $S_{V_{1}}$ and $S_{V_{2}}$ are the standard deviations and $r_{12}$ is the cross-correlation coefficient between the wind speed time series at two elevations. In practice, most often the crosscorrelation term in (7) is overlooked by assuming that there are no random fluctuations around the mean speed values which bring the implication that the standard deviations are equal to zero. These assumptions are not valid because in an actual weather, there are always fluctuations in the wind speed records as in Figure 1. By definition in statistics, the ratio of standard deviation to the arithmetic mean is the coefficient of variation, and hence (7) can be rewritten in parameterized form as,

$$
\left(\frac{Z_{1}}{Z_{2}}\right)^{n}=\left(\overline{\overline{V_{1}}} \overline{\overline{V_{2}}}\right)\left(1-C_{V_{1}} C_{V_{2}} r_{12}+C_{V_{2}}^{2}\right)
$$

Herein, $C_{V_{1}}$ and $C_{V_{2}}$ are the coefficients of variation for the wind speed records, $V_{1}$ and $V_{2}$, at two different elevations, respectively.

\section{Weibull Distribution Parameter Extrapolation}

Extrapolation of wind speed data to standard elevations poses a rather subjective approach based on the mean wind velocity only. Unreliability in such extrapolations is reflected in the subsequent wind energy, $E$, calculations through the classical formulation

$$
E=\frac{1}{2} \rho V^{3},
$$

where $\rho$ is the standard atmosphere air density which is equal to $1.226 \mathrm{gr} / \mathrm{cm}^{3}$ at $25^{\circ} \mathrm{C}$, and $V$ is the wind speed. Most often the wind speed at a meteorology station is measured along a tower at different elevations, and it is desired to be able to find the wind profile at this station for further wind loadings or energy calculations. Some researchers have employed the Weibull pdf for empirical wind speed relative frequency distribution (histogram), and a set of formulas are derived for the extrapolation of the Weibull pdf parameters [15-18]. In general, two-parameter Weibull pdf of wind speed, $P(V)$, is given as,

$$
P(V)=\left(\frac{k}{c}\right)\left(\frac{V}{c}\right)^{k-1} \exp \left[-\left(\frac{V}{c}\right)^{k}\right],
$$

where $k$ is a dimensionless shape parameter, and $c$ is a scale parameter with the speed dimension. In many applications, 


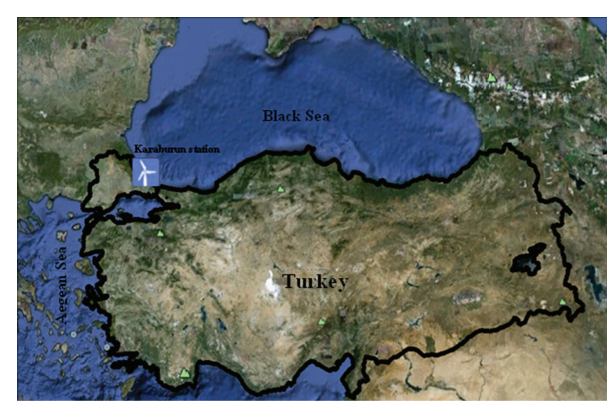

FIgure 2: The location of the Karaburun wind station.

the basic Weibull pdf statistical properties are the expectation, $E(V)$, variance, $\operatorname{Var}(V)$, and the $m$ th order moment $E\left(V^{m}\right)$ around the origin which are explicitly available as [19]

$$
\begin{gathered}
E(V)=c \Gamma\left(1+\frac{1}{k}\right), \\
\operatorname{Var}(V)=c^{2}\left[r\left(1+\frac{2}{k}\right)-r^{2}\left(1+\frac{1}{k}\right)\right], \\
E\left(V^{m}\right)=c^{m} \Gamma\left(1+\frac{m}{k}\right),
\end{gathered}
$$

respectively.

It is the purpose of this paper to present detailed extrapolation formulations for the Weibull pdf parameters on the basis of perturbation approach and power law of vertical wind velocity variation.

The two-parameter Weibull pdf has the average and standard deviation as in (11) and (12); and by definition their ratio gives the coefficient of variation as

$$
C_{V}=\sqrt{\frac{\Gamma(1+(2 / k))}{\Gamma^{2}(1+(1 / k))}-1} .
$$

The $k$ value can best be estimated by using the approximate relationship for (14) as given by Justus and Mikhail [17], that is:

$$
k=\frac{1}{C_{v}^{1.086}}
$$

and (11) yields the scale parameter as

$$
c=\frac{\bar{V}}{\Gamma(1+(1 / k))} .
$$

The substitution of these last two expressions for two elevations with labels 1 and 2 into (8) leads after some algebra to

$$
\left(\frac{Z_{1}}{Z_{2}}\right)^{n}=\left(\frac{c_{1}}{c_{2}}\right)\left[1-r_{12}\left(k_{1} k_{2}\right)^{-0.921}+k_{2}^{-1.841}\right] .
$$

By taking the logarithms of both sides, give

$$
n=\frac{\operatorname{Ln}\left(c_{1} / c_{2}\right)+\operatorname{Ln}\left[1-r_{12}\left(k_{1} k_{2}\right)^{-0.921}+k_{2}^{-1.841}\right]}{\operatorname{Ln}\left(Z_{1} / Z_{2}\right)} .
$$

Hence, once the Weibull pdf parameters, $c$ and $k$, are determined the power exponent can be calculated provided that the cross-correlation coefficient, $r_{12}$ is found from the available wind speed time series data. It must be noticed that this last expression reduces to the classical counterpart in (1) after the substitution of $k_{2}=0$. Therefore, this expression can be written as

$$
n=\frac{\operatorname{Ln}\left(c_{1} / c_{2}\right)}{\operatorname{Ln}\left(Z_{1} / Z_{2}\right)}
$$

\section{Application}

In this paper, wind speed data from the Karaburun wind station in Istanbul, Turkey are used, and this station is located at latitude $41.338^{\prime} \mathrm{N}$ and longitude $28.677^{\prime} \mathrm{E}$ (Figure 2). At this location hourly, wind speed measurements are available at three different heights $(10 \mathrm{~m}, 20 \mathrm{~m}$, and $30 \mathrm{~m})$ above the earth surface. The average wind speed, the standard deviation, and the coefficient of variation for each height are given in Table 2. Wind speed data measurement empirical relative frequency distribution functions (histograms) at $10 \mathrm{~m}, 20 \mathrm{~m}$, and $30 \mathrm{~m}$ are given together with the theoretically fitted Weibull pdf's in Figure 3 for each height. A good fit between the empirical and theoretical counterparts at different heights are obtained through the KolmogorovSmirnov test at significance level of 5\%. Table 1 presents the Weibull pdf parameters, $c$ (scale) and $k$ (shape). The scale parameters are 8.32, 8.77, and 9.54 for heights of $10 \mathrm{~m}, 20 \mathrm{~m}$, and $30 \mathrm{~m}$, respectively. The shape parameters are determined as 2, 2.11, and 2.06, respectively for the same heights.

It is clear from this table that as the height increases, the mean speed and standard deviation increase as expected. Coefficient of variation varies with different heights as in Table 2. This shows also that the closer the height to the earth surface, the greater is the instability of the air. The power law exponent, $n$, calculation between any two heights are found from (18) and classically from (19); and they are presented in Table 3.

For both classical and Weibull pdf approaches the greatest value lies between $20 \mathrm{~m}$ and $30 \mathrm{~m}$, whereas the lowest value is between $10 \mathrm{~m}$ and $20 \mathrm{~m}$. For all levels, the average values are 0.1360 and 0.1238 for classical and extended power laws, respectively.

\section{Conclusions}

A simple methodology on the basis of the perturbation theory is presented in order to derive an extended power law for the vertical wind speed extrapolation and then the Weibull probability distribution parameters. It is observed that on the contrary to the classical approach not only the means of wind speeds are at different elevations, but also the standard deviations and the cross-correlation coefficient should be taken into consideration, if the wind speeds at different elevations are not independent from each other. Otherwise, consideration of the classical power law in the calculations embodies the assumption that there are no fluctuations in the wind speed time series around their 


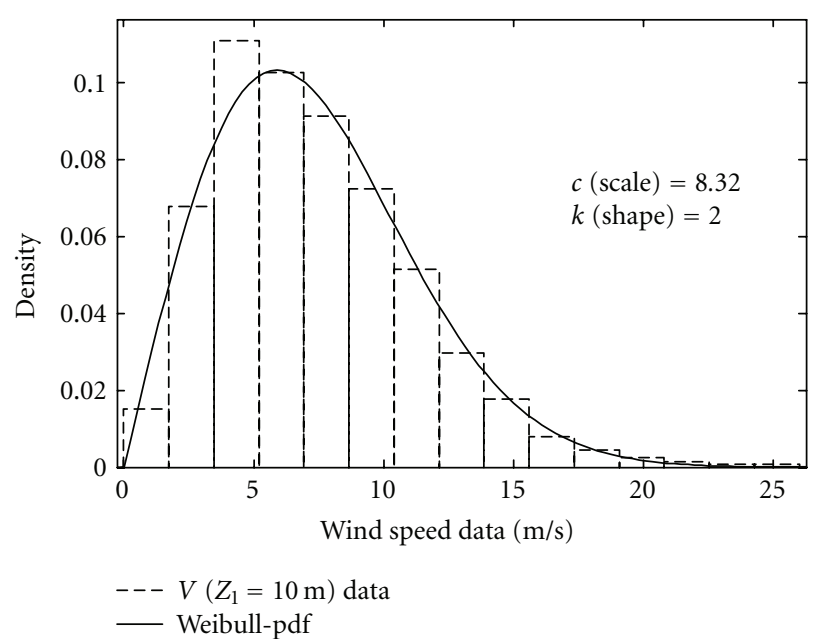

(a)

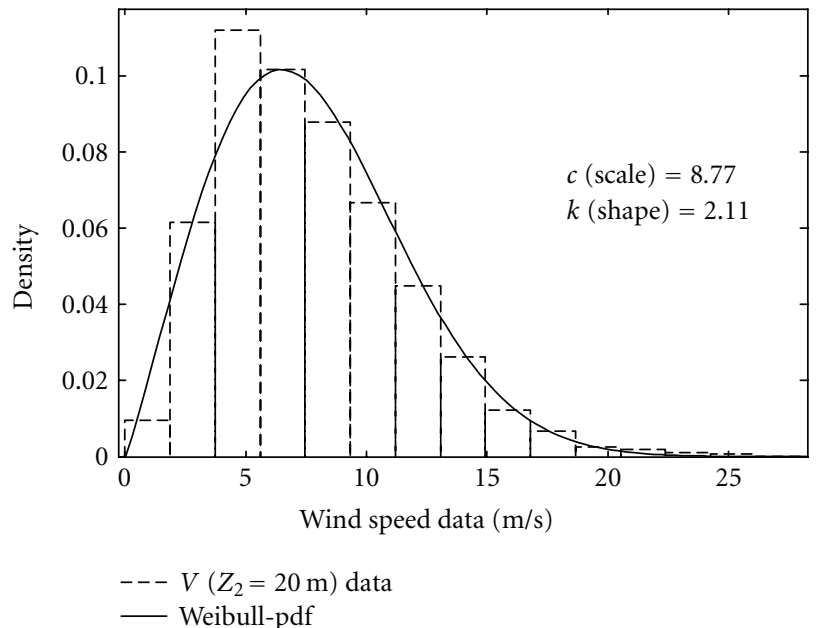

(b)

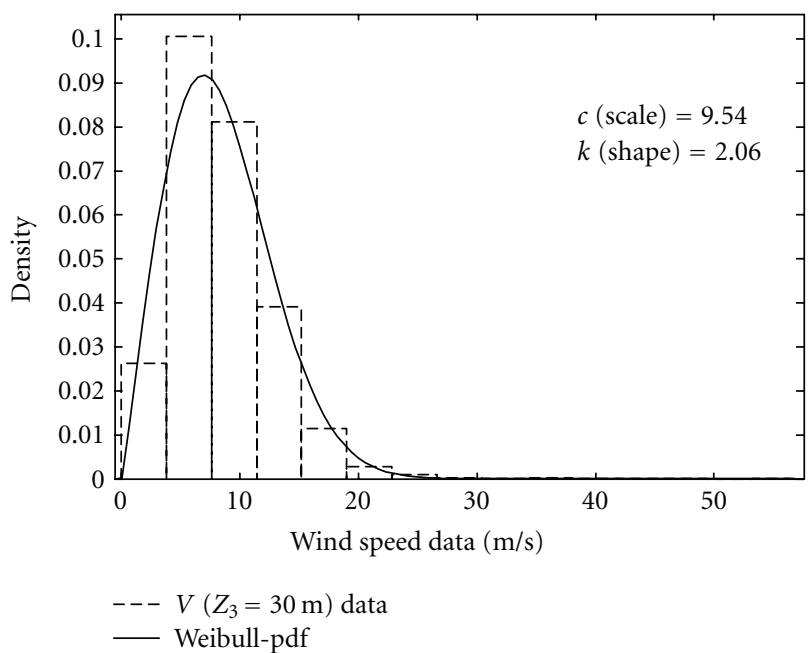

(c)

Figure 3: Karaburun Weibull pdf's at different levels.

TABLE 2: Wind speed summary statistics of Karaburun for three different heights.

\begin{tabular}{lcccc}
\hline $\begin{array}{l}\text { Height } \\
(\mathrm{m})\end{array}$ & $\begin{array}{c}\text { Mean speed } \\
(\mathrm{m} / \mathrm{s})\end{array}$ & $\begin{array}{c}\text { Standard deviation } \\
(\mathrm{m} / \mathrm{s})\end{array}$ & Coefficient of variation & \multicolumn{2}{c}{ Weibull pdf parameters } \\
\hline 10 & 7.37 & 3.86 & 0.52 & $k$ \\
20 & 7.75 & 3.88 & 0.50 & 8.32 \\
30 & 8.44 & 4.30 & 0.51 & 8.77 \\
\hline
\end{tabular}

TABLE 3: Exponent calculations both classical and extended power law.

\begin{tabular}{lcc}
\hline $\begin{array}{l}\text { Height } \\
(\mathrm{m})\end{array}$ & $\begin{array}{c}\text { Classical } \\
(19)\end{array}$ & $\begin{array}{c}\text { Extended } \\
(18)\end{array}$ \\
\hline $10-20$ & 0.0760 & 0.0935 \\
$20-30$ & 0.2076 & 0.1608 \\
$10-30$ & 0.1245 & 0.1172 \\
\hline Average & 0.1360 & 0.1238 \\
\hline
\end{tabular}

respective mean values. The necessary formulations for the Weibull distribution function wind speed parameter extrapolations are presented in this paper. The application of the developed methodology is presented for Karaburun, Istanbul, near the Black Sea coast wind speed measurement station data at three different levels.

\section{References}

[1] M. Motta, R. J. Barthelmie, and P. Vølund, "The influence of non-logarithmic wind speed profiles on potential power output at danish offshore sites," Wind Energy, vol. 8, no. 2, pp. 219-236, 2005. 
[2] A. Tindal, K. Harman, C. Johnson, A. Schwarz, A. Garrad, and G. Hassan, "Validation of GH energy and uncertainty predictions by comparison to actual production," in Proceedings of the AWEA Wind Resource and Project Energy Assessment Workshop, Portland, Ore, USA, September 2007.

[3] M. R. Patel, Wind and Solar Power Systems, CRC Press, 1999.

[4] M. R. Elkinton, A. L. Rogers, and J. G. McGowan, "An investigation of wind-shear models and experimental data trends for different terrains," Wind Engineering, vol. 30, no. 4, pp. 341-350, 2006.

[5] R. H. Kirchhoff and F. C. Kaminsky, "Wind shear measurements and synoptic weather categories for siting large wind turbines," Journal of Wind Engineering and Industrial Aerodynamics, vol. 15, no. 1-3, pp. 287-297, 1983.

[6] B. Turner and R. Istchenko, "Extrapolation of wind profiles using indirect measures of stability," Wind Engineering, vol. 32, no. 5, pp. 433-438, 2008.

[7] Minnesota Department of Commerce, "Wind resource analysis program (WRAP)," Minnesota Department of Commerce, St. Paul, Minn, USA, October 2002.

[8] G. Gualtieri and S. Secci, "Comparing methods to calculate atmospheric stability-dependent wind speed profiles: a case study on coastal location," Renewable Energy, vol. 36, no. 8, pp. 2189-2204, 2011.

[9] M. Hussain, "Dependence of power law index on surface wind speed," Energy Conversion and Management, vol. 43, no. 4, pp. 467-472, 2002.

[10] D. A. Spera and T. R. Richards, "Modified power law equations for vertical wind profiles," in Proceedings of the Conference and Workshop on Wind Energy Characteristics and Wind Energy Siting, Portland, Ore, USA, June 1979.

[11] A. S. Smedman-Högström and U. Högström, "A practical method for determining wind frequency distributions for the lowest $200 \mathrm{~m}$ from routine meteorological data," Journal of Applied Meteorology, vol. 17, no. 7, pp. 942-954, 1978.

[12] F. Bañuelos-Ruedas, C. Angeles-Camacho, and S. RiosMarcuello, "Analysis and validation of the methodology used in the extrapolation of wind speed data at different heights," Renewable and Sustainable Energy Reviews, vol. 14, no. 7, pp. 2383-2391, 2010.

[13] R. J. Barthelmie, "Evaluating the impact of wind induced roughness change and tidal range on extrapolation of offshore vertical wind speed profiles," Wind Energ, vol. 4, pp. 99-105, 2001.

[14] M. Motta, R. J. Barthelmie, and P. Vølund, “The influence of non-logarithmic wind speed profiles on potential power output at danish offshore sites," Wind Energy, vol. 8, no. 2, pp. 219-236, 2005.

[15] C. G. Justus, W. R. Hargraves, and A. Yalcin, "Nationwide assessment of potential output from wind powered generators," Journal of Applied Meteorology, vol. 15, no. 7, pp. 673678, 1976.

[16] C. G. Justus, W. R. Hargraves, and A. Mikhail, "Reference wind speed distributions and height profiles for wind turbine design and performance evaluation applications," ERDA ORO/5107$76 / 4,1976$.

[17] C. G. Justus and A. Mikhail, "Height variation of wind speed and wind distribution statistics," Geophysical Research Letters, vol. 3, pp. 261-264, 1967.

[18] A. Altunkaynak, T. Erdik, I. Dabanlı, and Z. Sen, “Theoretical derivation of wind power probability distribution function and applications," Applied Energy, vol. 92, pp. 809-814, 2012.
[19] K. Conradsen, L. B. Nielsen, and L. P. Prahm, "Review of Weibull statistics for estimation of wind speed distributions," Journal of Climate \& Applied Meteorology, vol. 23, no. 8, pp. 1173-1183, 1984. 

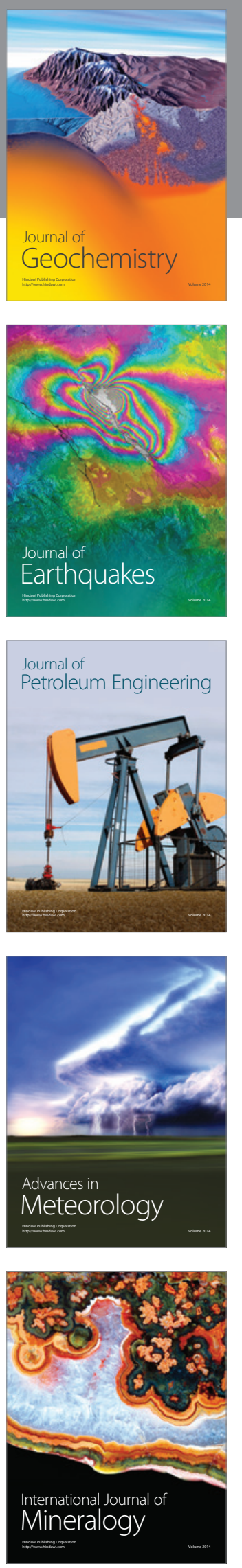
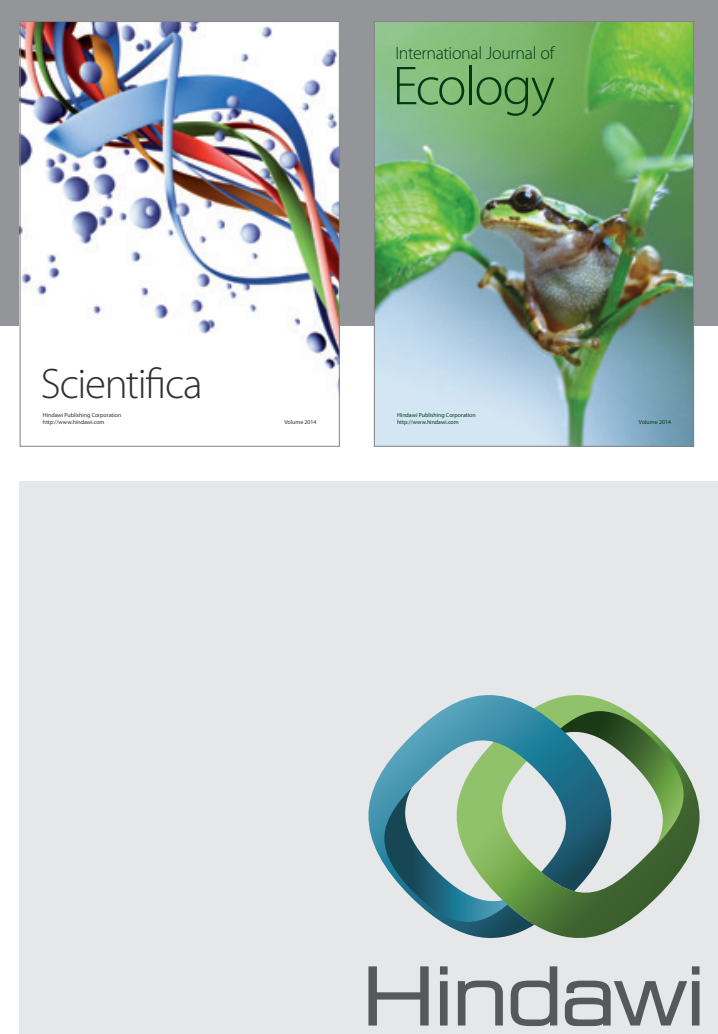

Submit your manuscripts at http://www.hindawi.com
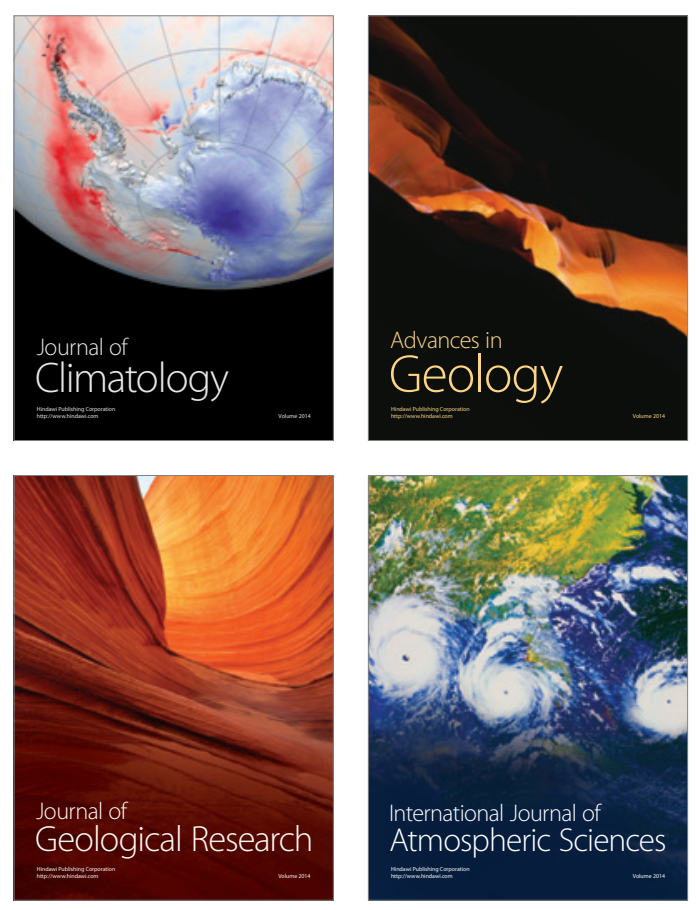
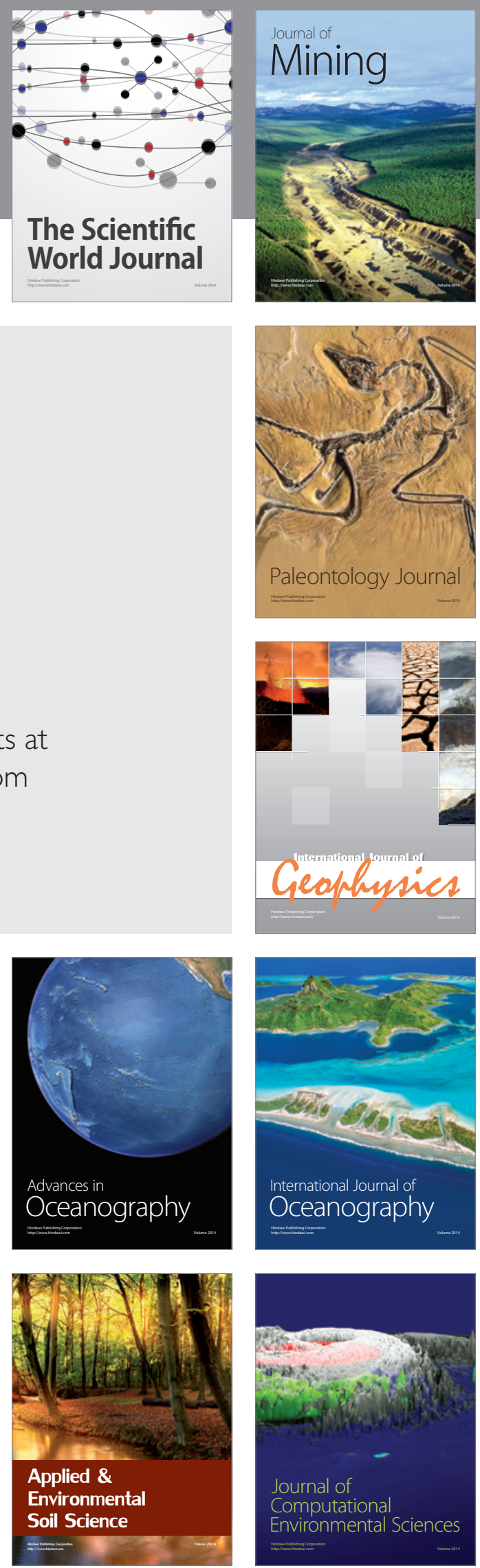